\title{
Difusión en el periodo de Desarrollo Regional: algunos aspectos de la iconografía Tumaco-Tolita
}

Diffusion pendant la Période de Développement régional : quelques aspects del 'iconographie Tumaco-Tolita

Diffusion in the period of Regional Development: some aspects of iconography Tumaco-Tolita

\section{María Fernanda Ugalde}

\section{OpenEdition}

Journals

Edición electrónica

URL: http://journals.openedition.org/bifea/3937

DOI: 10.4000/bifea.3937

ISSN: 2076-5827

\section{Editor}

Institut Français d'Études Andines

\section{Edición impresa}

Fecha de publicación: 1 diciembre 2006

Paginación: 397-407

ISSN: 0303-7495

\section{Referencia electrónica}

María Fernanda Ugalde, « Difusión en el periodo de Desarrollo Regional: algunos aspectos de la iconografía Tumaco-Tolita », Bulletin de l'Institut français d'études andines [En línea], 35 (3) | 2006, Publicado el 01 junio 2007, consultado el 01 diciembre 2020. URL : http://journals.openedition.org/ bifea/3937 ; DOI : https://doi.org/10.4000/bifea.3937

\section{(c) $(1) \odot$}

Les contenus du Bulletin de l'Institut français d'études andines sont mis à disposition selon les termes de la licence Creative Commons Attribution - Pas d'Utilisation Commerciale - Pas de Modification 4.0 International. 


\title{
Difusión en el periodo de Desarrollo Regional: algunos aspectos de la iconografía Tumaco-Tolita
}

\author{
María Fernanda Ugalde*
}

\begin{abstract}
Resumen
Determinados elementos de la iconografía Tolita-Tumaco se analizan aislados y se comparan y asocian con representaciones de dentro y fuera del estilo. Se parte de la hipótesis de que en el periodo de Desarrollo Regional, varias culturas de los Andes Centrales y Septentrionales comparten elementos de un ideario mitológico-religioso cuyas raíces podrían remontarse al horizonte Chavín. Tales elementos deberían estar presentes y ser reconocibles en las representaciones iconográficas de cada cultura, aún cuando aparezcan en diferentes grados de simplificación o abstracción.
\end{abstract}

Palabras clave: iconografía, Tolita-Tumaco, Desarrollo Regional

\section{Diffusion pendant la Période de Développement régional : quelques aspects de I’iconographie Tumaco-Tolita}

\section{Résumé}

Cet article analyse séparément certains éléments de l'iconographie La tolita Tumaco. Ceux-ci sont comparés et associés à des représentations appartenant à ce style ou à d'autres. L'hypothèse de départ est que durant la période de Développement régional plusieurs cultures des Andes centrales et septentrionales ont partagé des éléments faisant partie d'un ensemble d'idées mythologiques et religieuses dont certaines pourraient remonter jusqu’à Chavin. Ces éléments devraient être présents et reconnaissables dans les représentations iconographiques de chaque culture, même si elles sont présentes à des degrés variables de simplification ou d'abstraction.

Mots clés : iconographie, Tolita-Tumaco, Développement Régional 


\title{
Diffusion in the period of Regional Development: some aspects of iconography Tumaco-Tolita
}

\begin{abstract}
Certain elements of the Tolita-Tumaco iconography are analyzed as isolated elements and are compared and associated with representations of the same style as well as with other styles. The main hypothesis is that in the period of Regional Development, many of the cultures of the Central and Northern Andes share elements of a wider mythological-religious worldview, the roots of which may go back to the Chavín Horizon. Those elements should be present and be recognizable in the iconographic representations of each culture, even when they appear in different levels of simplification or abstraction.
\end{abstract}

Key words: iconography, Tolita-Tumaco, Regional Development

\section{INTRODUCCIÓN}

La riqueza simbólica de las imágenes de la cultura Tumaco-Tolita ha sido objeto de intensa discusión. Algunos de los aspectos iconográficos han sido tratados dentro de estudios más o menos extensos. Los trabajos tempranos pusieron énfasis en la elaboración de tipologías, para lo cual la clasificación se hizo en primera instancia tomando en cuenta más el aspecto tecnológico de la fabricación de las piezas (hueco o sólido, características de la pasta, etc.) que la representación iconográfica (Estrada, 1957; Sánchez Montañés, 1975; 1979; 1981). Estos estudios no profundizaron en el contenido simbólico de las representaciones. Así, Sánchez Montañés concluye que las figurillas serían un reflejo de la gente que vivió en estas sociedades, de su aspecto físico, sus costumbres al vestir y adornarse, su vida cotidiana y actividades así como del medio ambiente que los rodeó y la fauna con la que convivieron (Sánchez Montañés, 1981: 94). No parece del todo convincente este tipo de interpretación en vista de la recurrencia de determinados motivos y la ausencia de otros que también formaron parte de la cotidianeidad de la gente Tumaco-Tolita1. Evidentemente, las numerosas figurillas son obra de las manos de diferentes artistas. Sin embargo los motivos se repiten en alto número y frecuentemente con las mismas características. Nos parece, por tanto, que las figurillas se deben entender como representaciones simbólicas de conceptos, como parte de una cosmovisión. Asumimos que la redundancia de elementos o motivos responde a un conjunto de códigos cuyo significado era conocido para los integrantes de la sociedad en cuestión. Por esto creemos que, para poder llevar a cabo un análisis iconográfico, éste debe tomar en cuenta en primera instancia solamente los elementos inherentes a la representación misma. Es decir que resultan para nuestro objetivo irrelevantes datos como material o técnica con los que fueron producidos los objetos, y nos concentramos totalmente en la representación. Así, hay personajes que están representados tanto en placas de metal como en figurillas de cerámica, sean estas huecas o sólidas, y en este caso lo que nos interesa es el personaje y no su asociación tipológica.

En las últimas décadas han aparecido importantes aportes en este sentido, enfatizando en la importancia de la imagen misma y buscando, al momento de interpretar, puntos de comparación en otros estilos. De este modo, se ha hecho énfasis en la posible representación de cabezas trofeo (Di Capua, 2002a), en el papel del jaguar en los diferentes estilos de la costa ecuatoriana

1 En el material osteológico proveniente de las excavaciones realizadas en los sitios arqueológicos del área de estudio se han encontrado restos de fauna que no se reflejan en la iconografía. Por ejemplo algunos moluscos, así como animales del bosque tropical como el venado, no aparecen o están ínfimamente representados en el material arqueológico (Gutiérrez Usillos, 2002: 83 y ss., ver también Cadena \& Bouchard, 1980: 49). 
(Di Capua, 2002b) así como un exhaustivo recuento de la presencia de la fauna en las culturas precolombinas del actual Ecuador, que combina el dato arqueológico con el iconográfico (Gutiérrez Usillos, 2002). En esta misma línea deseamos profundizar en la investigación, haciendo uso de la semiótica2. La aplicación de la semiótica a los objetos arqueológicos consiste en entender a la figura como un todo compuesto de partes, donde cada parte constituye un signo (al que llamaremos aquí elemento) que porta una información. La redundancia de ciertos elementos nos hace suponer una importancia simbólica. La presencia de estos mismos elementos en otras áreas culturales nos hace pensar en algún tipo de relación. Se pone énfasis en el análisis comparativo, a partir de los mencionados elementos, con otros estilos, especialmente del área andina.

\section{EL SIGNO O ELEMENTO COMO UNIDAD Y PUNTO DE PARTIDA PARA LA COMPARACIÓN}

\section{1. Ejemplo 1: el animal lunar, iemigrante norteño?}

Como un primer ejemplo, aplicaremos el método descrito a una representación del estilo Tolita (fig. 1, izquierda). La pieza, famosa por la calidad y el material de la que fue fabricada (platino y oro), parece a primera vista la representación de un personaje único dentro del corpus de personajes conocidos. Sin embargo vale la pena desglosarlo y prestar atención a sus elementos constitutivos: está representado de perfil. La parte central de su cuerpo es una placa redonda móvil; lo que vendría a ser la columna vertebral es una línea curva constituida por puntos. Se ven dos extremidades, una superior y una inferior, que parecen antropomorfas. Tiene una larga cola. Su ojo es grande y de forma almendrada, y está enmarcado por una línea curva que termina en una voluta. La boca es grande, está abierta, y se ha enfatizado en representar la dentadura, abundante. Con la mano sostiene un objeto que se lleva a la boca. De su cabeza nace un largo anexo serpentiforme, que culmina con una cabeza, probablemente de serpiente. De su nariz también nace un anexo en forma de varias volutas.

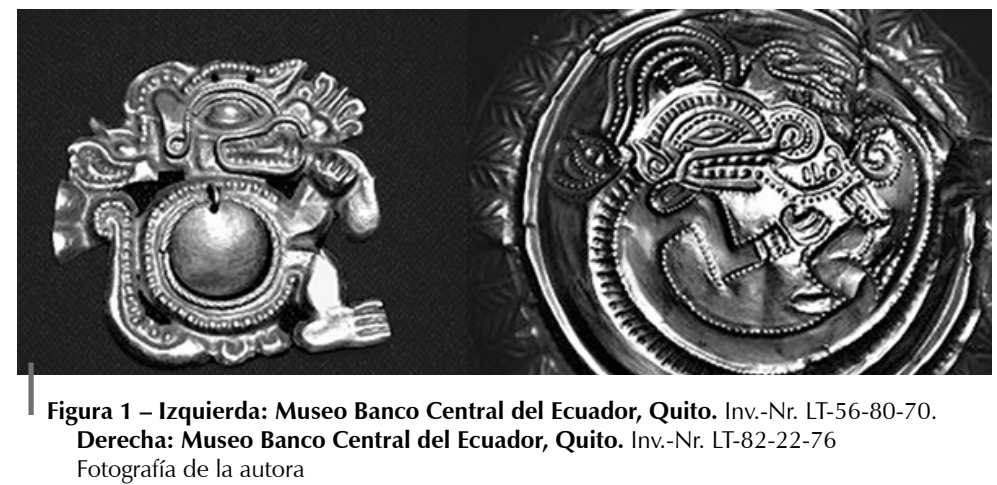

Buscando en el corpus del estilo de estudio (Tolita-Tumaco), nos encontramos con otra pieza en la que se encuentra un personaje en el que aparecen gran parte de los elementos arriba mencionados (fig. 1, derecha): la representación en perfil, el cuerpo curvo, el ojo grande almendrado, la boca grande con dentadura remarcada, las extremidades antropomorfas, el anexo serpentiforme sobre la cabeza. La cola se presenta aquí como una larguísima prolongación

2 Para una descripción detallada de la aplicación de la semiótica al análisis iconográfico de piezas arqueológicas precolombinas, ver Hohmann (2002). 
de la columna vertebral, y termina, al parecer, en una cabeza zoomorfa. Tiene la nariz en forma de espiral, elemento recurrente en personajes mitológicos de la costa ecuatoriana. Al igual que en la otra pieza, este personaje parece sostener con su mano un objeto que se lleva a la boca.

Podemos postular que se trata de dos representaciones de un mismo personaje. Es interesante que ambas se encuentran sobre un soporte metálico, y que no conocemos figuras de cerámica en las que aparezca con todas las características descritas. No obstante, tenemos un personaje zoomorfo que aparece frecuentemente en figuras de barro y en el que se pueden reconocer algunos de los elementos característicos mencionados. Se trata de un personaje que en la literatura se ha identificado como zarigüeya (Didelphis marsupialis; ver por ejemplo Cadena \& Bouchard, 1980: lám. VI; Sánchez Montañés, 1981: 19; Gutiérrez Usillos, 2002: 94 y ss.) (fig. 2).

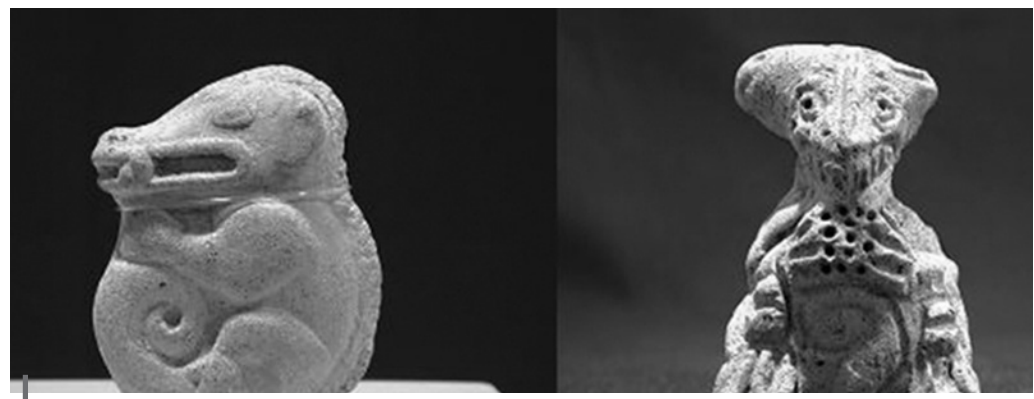

Figura 2 - Izquierda: Museo Banco Central del Ecuador, Esmeraldas. Inv.-Nr. LT-36-48-70. Derecha: Museo Banco Central del Ecuador, Quito. Inv.-Nr. LT-1338-2-60

Fotografía de la autora

Arriesgando más, desde el análisis comparativo, nos parece haber encontrado en otros estilos al mismo personaje que tenemos aquí en las representaciones sobre metal. Se trata del conocido «animal lunar», de la iconografía de Moche y Recuay. Aunque las convenciones de representación varíen, los elementos constitutivos característicos de este personaje se encuentran en uno y otro caso $^{3}$ (fig. 3). Gutiérrez Usillos reconoce características de la zarigüeya en el animal lunar de Recuay (Gutiérrez Usillos, 2002: 328), pero no lo asocia con el personaje Tolita como lo hemos hecho aquí, al cual califica de «grifo» (Gutiérrez Usillos, 2002: 100). Nos parece que en el estilo Tumaco-Tolita las representaciones de la zarigüeya y del personaje de la figura 1 están emparentadas. Podría postularse, por tanto, que nuestro «animal lunar» Tolita es un personaje fabuloso, posiblemente inspirado en la zarigüeya.

Como anotó ya Gutiérrez Usillos, los atributos de la zarigüeya en las piezas Tumaco-Tolita sugieren que este personaje pudo gozar del rol de héroe cultural, de manera similar al caso del tlacuache en la mitología mexicana4 (Gutiérrez Usillos, 2002: 329 y ss.; López Austin, 1990).

Volviendo al animal lunar (independientemente de que se acepte o no la sugerencia de su carácter de zarigüeya fantástica), el tema de la dirección en la que se pudo difundir el motivo

3 En un trabajo sobre el animal lunar en Moche, las autoras lo describen de la siguiente manera: «El Animal Lunar es uno de los animales mitológicos más prolíficos en la costa norte peruana, trazando su desarrollo iconográfico y rol cosmológico en un periodo de mil quinientos años. Se le puede conocer por las siguientes características: El Animal Lunar tiene: 1) cuatro patas; 2) largas salientes que se extienden de su cabeza y cola; 3) un hocico cuadrado; 4) clara y visible dentadura; 5) un cuerpo arqueado y sinuoso; 6) garras largas; y 7) una variedad de ornamentaciones como espalda y cola con remate dentado» (Mackey \& Vogel, 2003: 326). Esta descripción concuerda en todos los puntos con el personaje que hemos presentado.

4 Las representaciones de posibles zarigüeyas son abundantes en el corpus iconográfico Tolita-Tumaco, y comprenden un alto rango de variación, desde ejemplares básicamente zoomorfos y sin atributos que los caractericen, hasta otros, más o menos antropomorfizados, ataviados, y frecuentemente en asociación con atributos como una mazorca de maíz o algún fruto que se llevan a la boca, o masticando una soga. Gutiérrez Usillos plantea la posibilidad de que estas representaciones correspondan a escenas de una secuencia mítica: «representan escenas de un mito protagonizado por la zarigüeya, en el que, como en mitos contemporáneos, el animal asciende a los 
es difícil, sobre todo por la falta de una cronología refinada para el material Tolita. Sin embargo se puede intentar una aproximación con los datos existentes. Asumiendo que las piezas de metal en las que se encuentran los animales lunares Tolita puedan datarse en el periodo Tolita clásico -aprox. de 200 a.C. a 90 d.C. (Valdez 1987: 52 y ss.)-, éstas serían anteriores a las imágenes de Moche y Recuay. Si bien en Moche el animal lunar es un personaje temprano, presente ya en Moche I-II (Donnan \& McClelland, 1999, ver por ejemplo
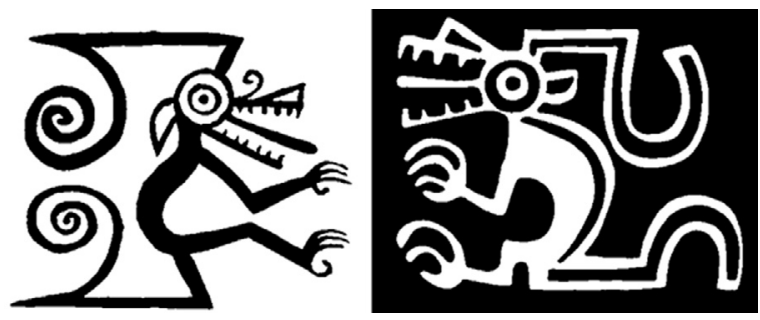

Figura 3 - Izquierda: Animal lunar, Moche I-II (tomado de Donnan \& McClelland, 1999: 192, fig. 6.7). Derecha: Animal lunar, Recuay (tomado de Makowski \& Rucabado, 2000: 214, fig. 38) figs. 2.22, 6.6., 6.7), estas fases están datadas aproximadamente a partir de 200 d.C. En la bibliografía disponible se asume que Moche adoptó el motivo del animal lunar de Recuay (Benson, 1997b: 102; también en Makowski \& Rucabado, 2000: 217 y ss.), y en Recuay la aparición del motivo debió tener lugar no antes de 200 d.C., ya que en estas fechas se data aproximadamente el comienzo del estilo. Si estos datos son correctos, la difusión de este motivo debió darse de norte a sur. El motivo posiblemente se desarrolló en Tolita, inspirado en la zarigüeya, pero dotado de un carácter divino o al menos fantástico, y se difundió hacia el sur ya como tal, lo cual explicaría por qué en Recuay y Moche tiene menos similitud con el animal inspirador. Falta profundizar la búsqueda del motivo hacia el norte y el sur, pues es posible localizarlo al menos tan al norte como en la cultura Coclé de Panamá y tan al sur como en la cultura Aguada del noroeste argentino.

Es interesante que las convenciones de representación de este personaje se rijan, en los distintos estilos, por estrictas normas. Así, en Tolita solo lo conocemos sobre un soporte de metal precioso y nunca lo vemos representado en cerámica ni en otro material. En Recuay, en cambio, lo conocemos solo en cerámica, pero restringido al horizonte pintado, jamás esculpido. En Moche parece haber más libertad en la representación del animal lunar, quien aparece en la mayoría de los casos pintado con la técnica de línea fina, pero hay al menos un caso en el que fue elaborado en arcilla con incrustaciones de madre perla (Benson, 1997b: 102, fig. 34) y otro en el que fue tallado en un pilar de madera (Makowski \& Rucabado, 2000: 219, fig. 44). Además, el animal lunar parece ser siempre una entidad independiente; se lo suele representar solo y sin interacción con otros personajes. En Moche nunca es parte de las escenas o secuencias narrativas, pero esta convención iconográfica probablemente se explica con razones cronológicas, pues en Moche el animal lunar es un motivo temprano y las secuencias narrativas son características de las fases tardías. Podemos concluir que se trata de un personaje mitológico que apareció probablemente por primera vez en la costa ecuatoriana, inspirado por la zarigüeya, y que se deslizó hacia el sur y hacia el norte, no sabemos si acompañado o no de toda su connotación inicial. En todo caso jugó un papel importante, sobre todo durante el periodo de Desarrollo Regional, en una vasta región del continente americano.

\section{2. Ejemplo 2: el «Picasso precolombino» y la decapitación ritual}

Otro personaje interesante es al asíllamado «Picasso precolombino» (Crespo \& Holm, 1977: 163) (fig. 4). En un primer paso descriptivo, tomando a la figura en su totalidad la podemos denominar «figura antropo-zoomorfa»5. Esta categoría es demasiado general y por tanto no es de gran ayuda para un análisis comparativo.

cielos, roba el maíz a los dioses, desciende por la soga, que posteriormente roe, para no ser perseguida y devora finalmente el maíz (o como héroe mítico, lo entrega a los hombres)» (Gutiérrez Usillos, 2002: 94).

5 Usamos esta terminología, pero con cierta precaución, pues tenemos presente la aclaración de Rowe (1962: 18) en referencia al arte de Chavín, quien cuestiona la interpretación de muchas de las representaciones como figuras 


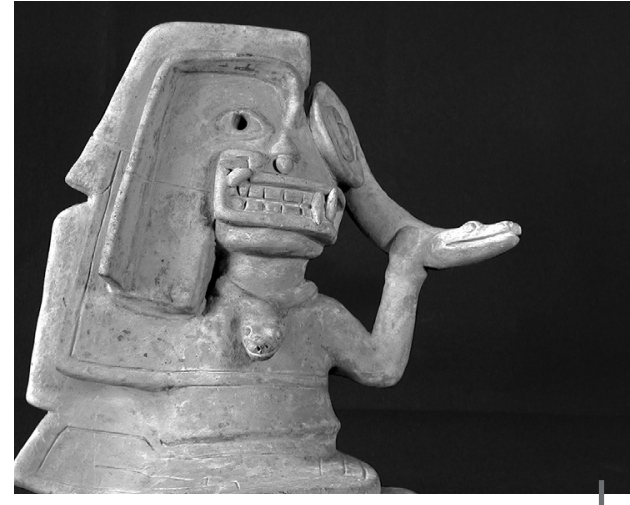

Figura 4 - Museo Banco Central del Ecuador, Quito

Inv.-Nr. LT-2-15-72

Fotografía de la autora
En un segundo paso aislamos los diferentes elementos constitutivos y buscamos posibles asociaciones para ellos por separado. Estos elementos constitutivos son:

- Vista lateral: estructura arquitectónica

- Serpiente saliendo del ojo

- Collar en forma de serpiente

- Paneles de colores (rojo, amarillo, verde)

- División dual de la figura (doble perspectiva)

- Dientes de felino

- Elemento geométrico («manto»)

La comparación a este nivel nos permite hacer las siguientes asociaciones (adelantamos ya que no hemos conseguido correlaciones para todos, sino solo para algunos de los elementos; el potencial de la pieza para profundizar en la comparación es amplio todavía).

Los dientes de felino aplicados a seres antropomorfos (o parcialmente antropomofos), son una característica muy frecuente en el área andina y se entienden como un símbolo representativo de los seres sobrenaturales (Rowe, 1962: 16). Hocquenghem (1987: 204) también interpreta de manera similar a los colmillos como representación del poder de las huacas. Podemos asumir entonces que se trata de la representación de un personaje que dispone de poderes sobrenaturales y que podría ser una divinidad.

La mitad derecha del personaje está dominada por un elemento geométrico que podría corresponder a un manto especial. Esta interpretación surgió como consecuencia de una larga búsqueda en el material Tumaco-Tolita de algún elemento comparable. Éste apareció finalmente en un personaje antropomorfo que lleva una cabeza humana pequeña entre sus manos, a la altura de su estómago (fig. 5) con al menos un ejemplar de éstos. El carácter del elemento geométrico como un manto o algún tipo de prenda de vestir se enfatiza en algunas piezas en las que la parte trasera fue decorada con incisiones.

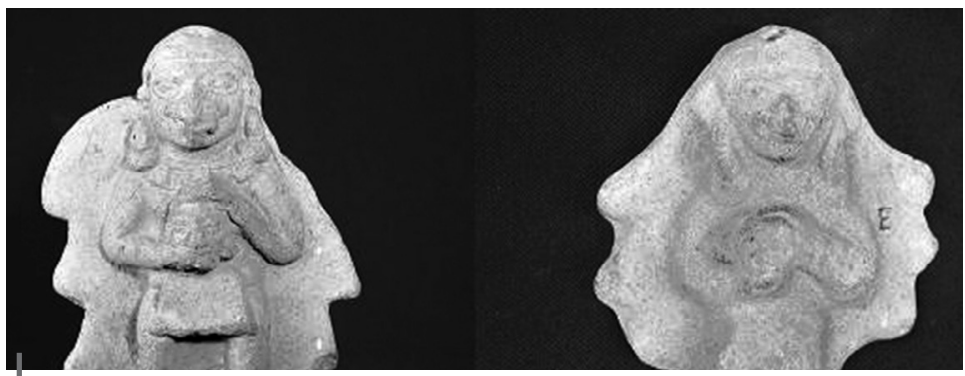

Figura 5 - Izquierda: Museo Banco Central del Ecuador, Quito. Inv.-Nr. LT-958-2-70 Derecha: Museo Banco Central del Ecuador, Guayaquil. Inv.-Nr. GA-126-969-78 Fotografía de la autora

Por medio de este elemento, entonces, se establece una relación entre la figura 4 y este personaje que llamaremos por ahora «decapitador» (aunque estamos conscientes de que el hecho de que lleve entre sus manos una cabeza no implica que se trate de la persona que habría

antropo-zoomorfas, cuando éstas son más bien antropomorfas o zoomorfas con un kenning perteneciente a otra categoría (por ejemplo dientes de felino). En el caso de la figura que se analiza aquí, en principio también se la podría definir como figura antropomorfa a la que se han aplicado elementos zoomorfos por sustitución (kennings). 
llevado a cabo una decapitación). Más interesante se vuelve la asociación en el momento en que continuamos la búsqueda de analogías para otro de los elementos.

La serpiente que emerge de uno de los ojos del personaje antropo-zoomorfo: este elemento está presente en la iconografía andina desde el Formativo ${ }^{6}$ y hay una pieza en especial que se asocia directamente con la figura 4. Se trata de una conocida estela de piedra del sitio Kuntur Wasi (Cajamarca, sierra norte de Perú) (fig. 6, izquierda), que además de este elemento comparte también con la figura 4 el de la dualidad de perspectiva en la composición. Y —aquí la relación con el punto anteriorla estela de Kuntur Wasi tiene una pequeña cabeza trofeo a la altura de su estómago, lo cual nos remite nuevamente al personaje del decapitador.

Al continuar la búsqueda de piezas con elementos
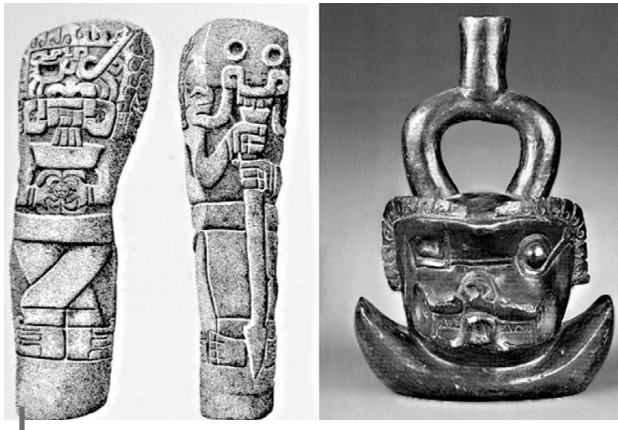

Figura 6 - Izquierda: estela de piedra de Kuntur Wasi (tomado de Burger, 1992: 112, fig. 102). Derecha: vasija del estilo Cupisnique, cerámica (tomado de Makowski, 2002) comparables a los componentes de la figura 4, nos encontramos con una serie de vasijas de

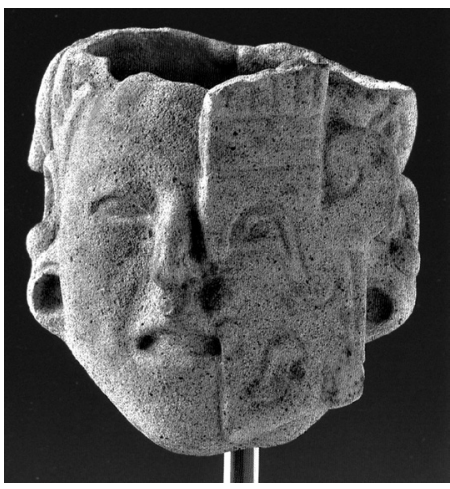
asa estribo del estilo Cupisnique (valle de Chicama, costa norte de Perú) que presentan analogías en varios aspectos (por ejemplo fig. 6, derecha. Ver también Burger, 1992: 96, fig. 83): división del rostro en dos partes, una zoomorfa y una antropomorfa; rasgos de felino en la parte zoomorfa; una serpiente encima de su ojo izquierdo. Además, son representaciones de cabezas, lo cual nos remite a las asociaciones con las cabezas trofeo y la decapitación. La vasija de la fig. 6 (derecha) muestra una cabeza con los elementos de la convencional representación del felino en el estilo Cupisnique, con excepción de su ojo izquierdo, que tiene exactamente el mismo elemento que nuestra figura 4; una serpiente se desenrosca y emerge de él.

Una forma diferente de división dual del rostro se encuentra en una figura de cerámica proveniente posiblemente de la isla La Tolita. Se trata de una cabeza antropomorfa cuya mitad izquierda está cubierta con una especie de máscara (fig. 7). Esta «media máscara» es, en contraste con la mitad humana, muy rígida, y su ojo tiene un apéndice grande en forma de voluta. Esta pieza parece querer transmitir la idea de transformación 7 . Resulta sumamente interesante que el lado del rostro que representa la transformación, aquel del que en este caso surge la voluta del ojo, es el lado izquierdo, el mismo que en la figura 4 así como en la estela de Kuntur Wasi y en las vasijas Cupisnique tiene a la serpiente saliendo del ojo. Me parece que estamos aquí frente a dos convenciones iconográficas de un mismo símbolo, es decir, que la voluta que surge del ojo del personaje de la máscara es una simplificación o abstracción de la serpiente en los otros casos, y que comparten un mismo campo semántico.

6 En numerosas imágenes provenientes del sitio Chavín de Huántar hay personajes que tienen serpientes sobre sus ojos, entre ellos la gran escultura de piedra conocida como «el lanzón», que pudo haber sido la deidad principal del Templo Antiguo de este complejo ceremonial (Rowe, 1962: 19; Burger, 1992: 136).

7 El uso de una máscara siempre tiene implícita la intención de transformarse en algo diferente a lo que se es; en este caso, la idea del artista parece ser la de enfatizar el momento mismo de la transformación, por lo que deja parte del rostro descubierto y permite así apreciar ambos caracteres. 


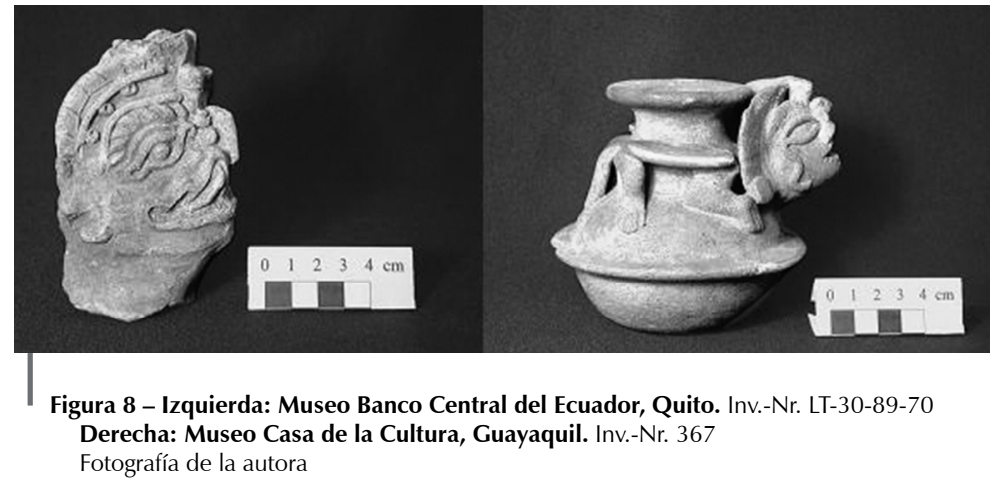

\section{DISCUSIÓN-DIFUSIÓN DE CONVENCIONES ICONOGRÁFICAS}

En la cultura Tolita es muy recurrente la existencia de un apéndice en el ojo de ciertos seres mitológicos, en forma de voluta (fig. 8), para los cuales se podría intentar la misma interpretación, es decir que esas volutas son una abstracción de la serpiente, y el ojo con la voluta el elemento portador del mismo significado simbólico que el ojo del que emerge la serpiente. Es importante enfatizar que esta voluta es un atributo exclusivo de seres sobrenaturales; nunca aparece en personajes netamente antropomorfos o zoomorfos (y esto no solo en el material Tolita-Tumaco sino también en las representaciones iconográficas de Chavín y de las culturas mesoamericanas donde también está presente). Por tanto se puede considerar característico de cierto tipo de seres, comparable por ejemplo con el halo de los santos en la iconografía cristiana.

La serpiente es, tal vez, el elemento iconográfico al que más interpretaciones se le han atribuido. Una de ellas es la asociación con la regeneración de la vida, con transformación (Benson, 1997a: 108; De la Garza, 2003: 133). El ojo con la serpiente (o su abstracción, ojo con apéndice de voluta), por lo que hemos visto, parece encajar en este campo semántico. Parece representar una transformación que de alguna manera se relaciona (o es precedida) por un ritual de decapitación. El ícono también podría caracterizar a los seres mitológicos que tienen que ver con esta práctica ritual.

La representación del personaje con la cabeza entre las manos da cabida a —al menos- dos posibilidades, la de un ritual de decapitación y la de la obtención de cabezas como trofeos, por ejemplo de guerra. Seguimos hablando de decapitación ritual de todos modos, porque consideramos que, aún en el caso de tratarse de trofeos, el hecho de decapitar a alguien y llevarse su cabeza como trofeo implica un acto ritualizado. La falta de material bélico en los yacimientos arqueológicos de las culturas Tumaco-Tolita y la relativa escasez de representaciones de guerreros, nos hace pensar más bien en una ofrenda de la cabeza decapitada a una divinidad. Esta divinidad podría ser la figura antropo-zoomorfa que estamos analizando (fig. 4).

Los «decapitadores» de Tolita tienen, con una sola excepción en el material revisado, rasgos totalmente antropomorfos. Se trata de un hombre que carga en sus manos una cabeza trofeo. Podría tratarse del representante de la divinidad entre los hombres, el sacerdote encargado de los rituales relacionados con esta divinidad. Por eso, como insignia, lleva su manto. En este punto cabe volver a la imagen y observarla lateralmente. Esta perspectiva recuerda a una estructura arquitectónica, un edificio con techo. Este elemento lateral debe contener también una información, podría por ejemplo aludir al templo en el que se rendía culto a la divinidad representada.

Queda abierta la cuestión de si la decapitación ritual en la cultura Tolita fue una práctica real o existió solo como parte de la mitología en alguna leyenda muy popular y divulgada8 (de manera

8 En este mismo sentido lo plantea Bouchard (2004: 57). 
análoga a la distribución de crucifijos y representaciones de la crucifixión en la iconografía cristiana, lo cual no implica que en todas las áreas culturales donde este objeto está presente se lleven a cabo realmente crucifixiones). Los hallazgos realizados en excavaciones arqueológicas hasta ahora no apuntan a la práctica real; los entierros del área cultural Tolita solo excepcionalmente presentan cráneos aislados ${ }^{9}$. Los mitos asociados a decapitación o a la obtención de cabezas trofeo son frecuentes en el área andina, sobre todo en culturas peruanas (Cerro Sechín, Cupisnique, Paracas, Nasca, Moche, menos implícitamente en Chavín), y su presencia en Tolita podría responder a una difusión de parte de este bagaje religioso-mitológico, que en las culturas peruanas tiene una tradición muy antigua. Esta difusión pudo tener lugar a través de las vías establecidas por contactos comerciales ${ }^{10}$ que mantuvieron, desde muy temprano, las culturas de la costa ecuatoriana con las peruanas. Estos contactos han sido extensamente estudiados, sobre todo alrededor de la concha Spondylus y el significado de ésta para las prácticas ceremoniales en los Andes Centrales, especialmente a partir del horizonte Chavín11 (Burger, 1992; Marcos 1986a; 1995). No hay evidencia de la extracción y el trabajo de la concha Spondylus en La Tolita (Alexandra Yépez, com. pers.), pero este producto con seguridad no fue el único comerciado. Las representaciones de canasteros y canoeros en piezas Tolita-Tumaco hablan a favor de que los mercaderes pudieron jugar un papel importante en la sociedad. Por estas vías comerciales pudo tener lugar el flujo de elementos iconográficos y las informaciones concernientes a ellos, aunque éstas probablemente sufrieron transformaciones en el camino.

Como hemos intentado demostrar, la comparación de elementos aislados permite asociar a los personajes con aquellos de otras culturas, y parece posible asumir que los elementos recurrentes contienen informaciones similares en los diferentes estilos, aun cuando las convenciones en las formas de representación varíen notablemente. Creemos que hay una serie de ideas que, sobre todo en el periodo de Desarrollo Regional (Intermedio Temprano) tuvieron una amplísima

9 La información al respecto de este tema es escasa y a veces no suficientemente clara, lo cual dificulta una afirmación o negación categórica sobre la práctica de decapitación ritual en el área cultural Tumaco-Tolita. Se encuentran en la literatura publicada alusiones a cabezas decapitadas, sin ofrecer datos detallados que permitan comprender el contexto. Barney Cabrera, en su reseña sobre el arte de Tumaco sostiene: «La arqueología ha descubierto indicios que permiten presumir el rito de la decapitación. Por ejemplo, en varias tumbas se han encontrado cráneos desprendidos o únicamente mandíbulas sin otros vestigios óseos» (Barney Cabrera, 1975: 242). No especifica la localización de las tumbas ni si éstas fueron documentadas mediante excavaciones arqueológicas. En el capítulo sobre iconografía de su informe publicado, Valdez (1987: 63) menciona que «la presencia de centenares de cráneos aislados, en contextos clásicos y tardíos, sugiere la práctica de decapitación ritual». Sin embargo, no hace alusión a estos hallazgos al describir los contextos funerarios excavados por él. Tampoco en el informe completo de excavación entregado por Leiva y Montaño al Instituto Nacional de Patrimonio Cultural consta ninguna información referente al hallazgo de cráneos aislados en tal volumen. En dicho informe (que incluye la descripción de cada uno de los cortes de excavación), se reportan, del cementerio tardío del sector Mango Montaño, tres enterramientos individuales con el cráneo separado del cuerpo (Leiva \& Montaño, 1994: 205), que de acuerdo a los estudios de antropología física citados allí, no tienen señales de corte en las vértebras cervicales (Leiva \& Montaño, 1994: 244). Además documentaron dos cráneos aislados en el sector H9 (Leiva \& Montaño, 1994: 266 , 268). Del texto se desprende que estos cráneos tampoco mantenían ninguna vértebra articulada, por lo cual falta la evidencia directa de decapitación. Aún de asumirla, el número de cráneos excavados no permite, a nuestro entender, sustentar la hipótesis de un ritual de decapitación como parte de la vida religiosa de la sociedad Tumaco-Tolita, menos si se toma en cuenta que los enterramientos excavados en la isla corresponden a diferentes periodos y abarcan un rango temporal de cerca de mil años, aprox. entre 700 a.C. y 350 d.C. (Valdez, 1987: 55). La evidencia arqueológica de otras regiones del área de estudio tampoco sugiere una práctica ritual generalizada de decapitación. En la región de Tumaco (Monte Alto), Cubillos excavó un montículo con enterramientos, entre los que encontró dos cráneos aislados sin mandíbula inferior (Cubillos, 1955: 134). Patiño, que realizó excavaciones en la zona costera de Tumaco, solo encontró enterramientos secundarios en urnas (Patiño, 2003: 68s.). Por tanto, el tema de la práctica real de decapitación ritual en las culturas Tumaco-Tolita queda aún por aclararse y faltarían datos más concretos para asumir su existencia.

10 Los intercambios comerciales se entienden en el sentido de Renfrew, como portadores de un flujo de información (Renfrew, 1975).

11 Se entiende aquí al horizonte Chavín en los términos planteados por Burger, quien defiende el valor heurístico del concepto. No se propone de ninguna manera algún tipo de influencia del ente político Chavín en la sociedad de Tumaco-Tolita. La difusión a la que nos referimos la entendemos en la misma línea de Burger cuando anota, 
divulgación, al menos a lo largo del área andina. Este imaginario (de índole claramente religiosa) pudo tener su origen en el horizonte Chavín y haber gozado de una gran popularidad en la época posterior, lo que determinó la absorción de al menos parte de los elementos en un área bastante grande. Por tanto tiene mucho sentido hacer el esfuerzo de comparar más allá de los estilos vecinos, con el fin de adquirir una visión más clara del desarrollo del pensamiento y de los lazos entre las culturas.

\section{Referencias citadas}

BARNEY CABRERA, E., 1975 - Tumaco, abstracción y realismo. In: Historia del arte colombiano, tomo I; Bogotá: Salvat Editores Colombiana S. A.

BENSON, E., 1997a - Birds and Beasts of Ancient Latin America, 181 p.; Gainesville: University Press of Florida.

BENSON, E. (ed.), 1997b - The Spirit of Ancient Peru, 216 p.; Londres/Nueva York: Thames and Hudson.

BOUCHARD, J.-F., 2004 - Sacrificios y chamanismo en la cultura Tumaco-La Tolita. In: Simbolismo y ritual en los Andes Septentrionales (Guinea, M., ed.): 51-68; Quito: Abya-Yala.

BURGER, R., 1989 - El horizonte Chavín: ¿Quimera estilística o metamorfosis socioeconómica? Revista Andina, 7(2): 543-573; Cusco: Centro de Estudios Rurales Andinos Bartolomé de las Casas.

BURGER, R., 1992 - Chavín and the Origins of Andean Civilization, 248 p.; Londres: Thames and Hudson.

CADENA, A. \& BOUCHARD, J.-F., 1980 - Las figurillas zoomorfas de cerámica del Litoral Pacífico Ecuatorial. Boletín del Instituto Francés de Estudios Andinos, 9 (3-4): 49-68; Lima.

CRESPO, H. \& HOLM, O. (ed.), 1977 - Arte precolombino del Ecuador, 260 p.; Barcelona/ Quito: Salvat.

CUBILLOS, J. C., 1955 - Tumaco, notas arqueológicas, 145 p.; Bogotá: Editorial Minerva Ltda.

DE LA GARZA, M., 2003 - El universo sagrado de la serpiente entre los mayas, 462 p.; México D.F.: UNAM.

Di CAPUA, C., 2002a - Las cabezas trofeo: un rasgo cultural en la cerámica de La Tolita y de Jama Coaque y breve análisis del mismo rasgo en las demás culturas del Ecuador precolombino. In: De la imagen al ícono. Estudios de Arqueología e Historia del Ecuador: 23-93; Quito: Abya-Yala.

Di CAPUA, C., 2002b - El chamán y el jaguar: Iconografía de la cerámica prehistórica de la Costa ecuatoriana. In: De la imagen al icono. Estudios de Arqueología e Historia del Ecuador: 119-134; Quito: Abya-Yala.

DONNAN, C. \& McCLELLAND, D., 1999 - Moche Fineline Painting. Its Evolution and Its Artists, 320 p.; Los Angeles: UCLA Fowler Museum of Cultural History.

ESTRADA, E., 1957 - Prehistoria de Manabí, 176 p.; Guayaquil: Museo Víctor Emilio Estrada.

GUTIERREZ USILLOS, A., 2002 - Dioses, símbolos y alimentación en los Andes. Interrelación hombre-fauna en el Ecuador prehispánico, 473 p.; Quito: Abya-Yala.

al referirse a sitios no pertenecientes al horizonte pero cuya cultura material está estilísticamente relacionada: «La existencia de elementos artísticos compartidos es explicable en términos de redes de intercambio interregional y de comunicación» (Burger, 1989: 552). Este mismo tipo de argumentación es utilizado por Marcos (1986b) para explicar la coincidencia de elementos iconográficos entre culturas de la costa ecuatoriana del periodo de Desarrollo Regional (Tolita y Jama Coaque) y aquellas sincrónicas del occidente de México. 
HOCQUENGHEM, A. M., 1987 - Iconografía Mochica, 280 p.; Lima: Fondo Editorial PUCP.

HOHMANN, C., 2002 - Was macht das Mondtier auf dem Trichterrand? Gedanken zur Systematik der Bildkonstruktion in der Recuay-Ikonographie; Berlín: Universidad Libre de Berlín. Tesis de maestría.

LEIVA, S. \& MONTAÑO, M. C., 1994 - Informe final del Proyecto Arqueológico «La Tolita»; Quito: Banco Central del Ecuador. Informe inédito.

LÓPEZ AUSTIN, A., 1990 - Los mitos del Tlacuache. Caminos de la mitología mesoamericana; 542 p.; México: Alianza Editorial Mexicana.

MACKEY, C. \& VOGEL, M., 2003 - La luna sobre los Andes: Una revisión del animal lunar. In: Moche: hacia el final del milenio. Actas del Segundo Coloquio sobre la Cultura Moche (Trujillo, 1 al 7 de agosto de 1999) (Uceda, S. \& Mujica, E., eds.), tomo I: 325-342; Lima: Universidad Nacional de Trujillo, Pontificia Universidad Católica del Perú.

MAKOWSKI, K. (ed.), 2002 - Los Dioses del antiguo Perú; Lima: Banco de Crédito del Perú.

MAKOWSKI, K. \& RUCABADO, J., 2000 - Hombres y deidades en la iconografía Recuay. In: Los Dioses del antiguo Perú (Makowski, K., ed.): 214 y ss.; Lima: Banco de Crédito del Perú.

MARCOS, J., 1986a - De ida y vuelta a Acapulco con mercaderes de mullu. In: Arqueología de la costa ecuatoriana: Nuevos enfoques (Marcos, J., ed.): 163-496; Quito: ESPOL-Corporación Editora Nacional. Biblioteca Ecuatoriana de Arqueología I.

MARCOS, J., 1986b - El viejo, la serpiente emplumada, el señor de las aguas o Tlaloc en la iconografía del Área Septentrional Andina. In: Arqueología de la costa ecuatoriana: Nuevos enfoques (Marcos, J., ed.): 205-229; Quito: ESPOL-Corporación Editora Nacional. Biblioteca Ecuatoriana de Arqueología I.

MARCOS, J., 1995 - El mullu y el pututu: La articulación de la ideología y el tráfico a larga distancia en la formación del Estado Huancavilca. In: Primer Encuentro de Investigadores de la Costa Ecuatoriana en Europa (Álvarez, A. et al., eds.): 97-142; Quito: Abya-Yala.

PATIÑO, D., 2003 - Tumaco prehispánico. Asentamiento, subsistencia e intercambio en la costa pacífica de Colombia, 257 p.; Popayán: Editorial Universidad del Cauca. Serie Estudios Sociales.

RENFREW, C., 1975 - Trade as Action at a Distance: Questions of Integration and Communication. In: Ancient Civilizations and Trade (Sabloff, J. \& Lamberg-Karlowsky, C., eds.): 3-59; Albuquerque: University of New Mexico Press.

ROWE, J., 1962 - Chavín Art. An Inquiry into its Form and Meaning, 40 p.; Nueva York: The Museum of Primitive Art.

SABOLO, Y., 1986 - Tumaco. 1000 ans d'art Précolombien, 252 p.; Fribourg.

SÁNCHEZ MONTAÑÉS, E., 1975 - Notas sobre el significado artístico de las figurillas cerámicas de la costa de Esmeraldas (Ecuador). In: $1^{\text {era }}$ Reunión de Antropólogos Españoles: 79-87; Sevilla: Publicaciones de la Universidad de Sevilla.

SÁNCHEZ MONTAÑÉS, E., 1979 - Una placa ritual de la cultura Tumaco-Tolita. In: Actas del XLII Congreso Internacional de Americanistas, vol. IXa: 273-282; París.

SÁNCHEZ MONTAÑÉS, E., 1981 - Las figurillas de Esmeraldas: tipología y función. Memorias de la Misión Arqueológica Española en el Ecuador, vol. VII, 120 p.; Madrid: Ministerio de Asuntos Exteriores.

VALDEZ, F., 1987 - Proyecto Arqueológico «La Tolita» (1983-1986); Quito: Banco Central del Ecuador. 